\title{
Contextualização na Perspectiva da Inclusão do Surdo Usuário da Libras
}

\author{
PEREIRA, Aurinete Barbosa Mulato ${ }^{1}$ \\ REIS, Edmerson dos Santos ${ }^{2}$
}

\section{RESUMO}

Este artigo tem como objetivo suscitar reflexões sobre os processos de ensino aprendizagem na perspectiva da contextualização, na especificidade da Educação de surdos usuários da Língua Brasileira de Sinais (LIBRAS). Busca mostrar que a contextualização não é algo aplicável apenas nas escolas rurais como aparece nos discursos e nas literaturas da região do semiárido. A contextualização pode estar presente em todas as ações educacionais, independente de série, local ou condição do aluno. Para exemplifica essa afirmação será apresentada uma questão de física, na qual o professor ensinou - aluno a resolver a situação problema, pautado nos procedimentos metodológicos da contextualização dos signos presentes na elaboração da questão. O estudo tem uma abordagem qualitativa, sendo descritiva na sua forma de apresentar os resultados. De acordo com o estudo é possível observar que os alunos surdos têm suas particularidades na forma de apreender a língua. Por isso a contextualização das palavras é fundamental para a compreensão do conteúdo em exercício, que deve acontecer de forma bilíngue Português/LIBRAS.

Contextualização. Aprendizagem. Aluno Surdo. LIBRAS.

\section{Contextualization from the perspective of the inclusion of the deaf user of libras}

\section{ABSTRACT}

This article aims to raise reflections on the teaching-learning processes from the perspective of contextualization, in the specificity of the Education of deaf users of the Brazilian Sign Language (LIBRAS). It seeks to show that contextualization

\footnotetext{
${ }^{1}$ Mestranda em Educação, Cultura e Territórios Semiáridos, da Universidade do Estado da Bahia - UNEB. Email: aurinetemulato@hotmail.com. Lattes: http://lattes.cnpq.br/1634153950625675. Orcid: https://orcid.org/0000-0001-8441-9420.

2 Doutor em Educação pela Universidade Federal da Bahia (2009). Professor Titular do Departamento de Ciências Humanas - DCH-III/Universidade do Estado da Bahia. Email: edmerson.uneb@gmail.com. Lattes: http://lattes.cnpq.br/4799013495727395. Orcid: https://orcid.org/0000-0003-3153-6759.
} 
is not only applicable in rural schools as it appears in the speeches and literature in the semiarid region. The contextualization can be present in all educational actions, regardless of grade, location or condition of the student. To exemplify this statement, a physics question will be presented, in which the teacher taught the student to solve the problem situation, based on the methodological procedures of contextualizing the signs present in the elaboration of the question. The study has a qualitative approach, being descriptive in its way of presenting the results. According to the study, it is possible to observe that deaf students have their particularities in the way of learning the language. For this reason, the contextualization of words is fundamental for the understanding of the content in exercises, which must happen in a bilingual way - Portuguese/LIBRAS.

Contextualization. Learning. Deaf Student. LIBRAS.

\section{Contextualización en la perspectiva de la inclusión del sordo usuario de libras}

\section{RESUMEN}

Este artículo tiene como objetivo plantear reflexiones sobre los procesos de enseñanza-aprendizaje desde la perspectiva de la contextualización, en la especificidad de la Educación de sordos usuarios de la Lengua de Signos Brasileña (LIBRAS). Busca mostrar que la contextualización no solo es aplicable en las escuelas rurales como aparece en los discursos y la literatura en la región semiárida. La contextualización puede estar presente en todas las acciones educativas, independientemente del grado, ubicación o condición del alumno. Para ejemplificar este enunciado, se presentará una pregunta de física, en la cual el docente enseñó al alumno a resolver la situación problema, a partir de los procedimientos metodológicos de contextualización de los signos presentes en la elaboración de la cuestión. El estudio tiene un enfoque cualitativo, siendo descriptivo en su forma de presentar los resultados. Según el estudio, es posible observar que los estudiantes sordos tienen sus particularidades en la forma de aprender el idioma. Por ello, la contextualización de las palabras es fundamental para la comprensión del contenido en ejercicio, que debe suceder de forma bilingüe - Portugués/LIBRAS.

Contextualización. Aprendizaje. Alumno sordo. LIBRAS.

\section{Contestualizzazione nell'ottica dell'inclusione dell'utente sordo di libbra}

\section{SOMMARIO}

Questo articolo si propone di sollevare riflessioni sui processi di insegnamentoapprendimento dal punto di vista della contestualizzazione, nella specificità dell'Educazione degli utenti sordi della Lingua dei Segni Brasiliana (LIBRAS). Cerca di dimostrare che la contestualizzazione non è applicabile solo nelle scuole rurali come appare nei discorsi e nella letteratura nella regione semi-arida. La

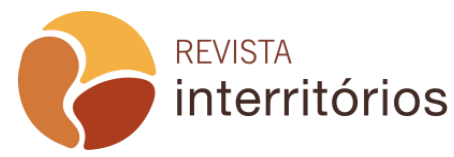

Interritórios | Revista de Educação Universidade Federal de Pernambuco, Caruaru, BRASIL | V.6 N.12 [2020] 
contestualizzazione può essere presente in tutte le azioni educative, indipendentemente dal grado, dall'ubicazione o dalle condizioni dello studente. Per esemplificare questa affermazione, verrà presentata una domanda di fisica, in cui il docente insegnava allo studente a risolvere la situazione problematica, sulla base delle procedure metodologiche di contestualizzazione dei segni presenti nell'elaborazione della domanda. Lo studio ha un approccio qualitativo, essendo descrittivo nel suo modo di presentare i risultati. Secondo lo studio, è possibile osservare che gli studenti sordi hanno le loro peculiarità nel modo in cui apprendono la lingua. Pertanto, la contestualizzazione delle parole è essenziale per la comprensione del contenuto in esercizio, che deve avvenire in modo bilingue - Portoghese/LIBRAS.

Contestualizzazione. Apprendimento. Allievo sordo. LIBBRE.

\section{INTRODUÇÃO}

No universo educacional, inúmeros são os desafios enfrentados todos os dias pelos professores, os quais exigem ação reflexão e ação. A prática pedagógica é efetivada impulsionada pelas inovações diárias. Inovações pensadas externamente e impostas e inovações que as realidades evocam. A segunda surge no sentido de encontrar estratégias que "garantam" a aprendizagem significativa do aluno, mas que quase nunca são sistematizadas e legitimadas no currículo, e/ou concebida cientificamente, dada as diversas realidades existentes.

O exercício docente requer cada vez mais a tomada de consciência dessas diversidades porque, quanto mais o professor tomar consciências dessas diversidades (de saberes, realidades, culturas, múltiplas identidades e sujeitos, etc.), mais fácil será encontrar meios que viabilizem o alcance das metas e dos resultados desejados para a aprendizagem. Ou seja, desenvolver estratégias adequadas para que cada sujeito (em sua realidade) aprenda de forma significativa.

E nesse caminhar, o desafio posto aos docentes é o de encontrar melhores condições para que o professor consiga estimular, instrumentalizar e avaliar o processo de aprendizagem de cada aluno dentro de suas especificidades.

Diante do exposto, outro objeto de reflexão deve ser, as concepções de aprendizagens. Refutando aqui as ideias de assimilação e reprodução mecânica dos conteúdos, salientamos que estas, não dão sentido ao saber, não estimulam à pesquisa, à problematização, tão pouco, à aplicabilidade dos conhecimentos. $\mathrm{O}$ sujeito fica alheio às funcionalidades do saber, porque, tradicionalmente, ele não é conectado à sua vida prática, com suas relações, com seu meio, com as pessoas que o cercam, com o seu lugar no mundo. Assim, é nesse sentido que apontamos a contextualização como procedimento pedagógico indispensável ao 
processo de ensino aprendizagem, isso em qualquer área do conhecimento ou localização da escola.

Nesse estudo apresentaremos uma sequência didática sobre o conteúdo "cinemática" 3 da disciplina de física, destacando o passo a passo que o professor seguiu para socializar o conteúdo com clareza, objetividade, funcionalidade e garantir o entendimento e a aprendizagem do aluno. Nesse processo enfatizaremos a importância da contextualização que fez toda diferença na compreensão do aluno, pois a mesma permitiu ir além da física, para poder conseguir situar o aluno no tempo/espaço. Esse procedimento perpassou a interdisciplinaridade, permitindo uma visão holística da situação problema estudada.

A discussão ainda é ínfima. Não temos pretensão de ditar receitas nessa área. Esse trabalho é apenas um relato de experiência que consideramos de grande relevância para o ensino aprendizagem da pessoa com surdez e para educação quando o foco for a contextualização, principalmente para chamar atenção para aqueles que discutem essa proposta sempre se referindo à educação do campo.

Quando tratamos de educação para o aluno surdo, a adoção do procedimento de contextualização surge como estratégia fundamental para materializar os conceitos, representações que estão implícitos e/ou explícitos em comandos, conteúdos, exercícios e situações problemas. No caso da educação de surdos, a contextualização será realizada com base no uso de imagem, atividades repetitivas e como nas demais realidades, no "contexto" e na perspectiva da "interdisciplinaridade".

De modo sucinto, apresentaremos a aula de física que acompanhamos durante uma semana. Será destacada a contextualização do conteúdo, feita pelo professor, para construir o entendimento do aluno. A contextualização foi realizada de forma natural, não intencional, evocada pela situação, mas muito bem estruturada, na condição e realidade do aluno.

\section{Identificando os conceitos de contextualização}

A contextualização é um conceito que orienta a educação sob os princípios da valorização das vivências locais articuladas aos contextos globais. O processo de sistematização dos conteúdos e das metodologias adotadas, inicia-se sempre, do local para o global. Na região do semiárido brasileiro, essa

\footnotetext{
${ }^{3}$ Física: ramo da mecânica que estuda o movimento de corpos ou partículas, sem referência a massas ou a forças. 
proposta nasce da inquietação causada pela descontextualização excludente vivida pelo povo dessa região.

As discussões sobre a contextualização, realizadas nos estudos da região do semiárido brasileiro, estão pautadas na organização de um currículo que defende ações afirmativas positivas sobre esse contexto, buscando a construção de uma educação para convivência nessa região, que deve envolver a educação nas escolas urbanas e rurais, afinal o semiárido brasileiro também é formado por grandes centros urbanos. Porém, observa-se que, na maioria das vezes, os discursos estão sempre atrelados à educação do campo, limitando, em alguns casos, a educação contextualizada à educação do/no campo.

É importante ressaltar que essa concepção de educação pode e deve ser adotada em qualquer realidade, seja ela urbana ou rural. Considerando que:

Contextualizar. Ato de colocar no contexto. Do latim contextu. Colocar alguém a par de algo, alguma coisa, uma ação premeditada para situar um indivíduo em um lugar no tempo e no espaço desejado, encadear ideias em um escrito, constituir o texto no seu todo, argumentar (FAZENDA, 2002, p. 40).

A seguir apresentamos um pouco das produções conceituais referentes a contextualização, mostrando o modo como os autores caracterizam a temática. Em seguida, faremos algumas anotações sobre o que entendemos por contextualização e como que o referido conceito pode se expandir no processo de ensino aprendizagem, ultrapassando os limites do campo, local, ambiental, rural etc., fazendo uso dos mesmos conceitos de base da educação contextualizada, nessa realidade camponesa.

Em nosso levantamento, identificamos a ideia de contextualização entendida como forma de descolonização do ensino, o qual está demasiadamente descontextualizado porque tem sido pensado majoritariamente numa lógica da realidade sudeste, região que concentra a indústria editorial e midiática, a qual produz e distribui narrativas hegemônicas, desconsiderando as especificidades regionais, clima, cultura, povos, etc. (MARTINS, 2006). Esse entendimento busca romper com a "contextualização" feita a partir de uma realidade de uma elite, em geral, uma prática colonizadora.

Contextualizar, portanto, é esta operação mais complicada de descolonização. Será sempre tecer o movimento de uma rede que concentre o esforço em soerguer as questões "locais" e outras tantas questões silenciadas na narrativa oficial, ao status de "questões pertinentes" não por serem elas "locais" ou "marginais", mas por serem elas "pertinentes" e por representarem a devolução da "voz" aos que tiveram usurpada, roubada, negada historicamente (MARTINS, 2006, p.53). 
Compreendido essa afirmação, fica claro que podemos pensar, por essa vertente, a educação como um todo, afinal as escolas urbanas também são vítimas dessa indústria do sudeste, pois, os livros vêm de lá, com todas as suas ideologias e colonizações. E não foram apenas os camponeses que tiveram suas vozes roubadas. Como o próprio Martins (2006) destaca, nesta lista estão os índios, quilombolas, mulheres, populações periféricas e pode-se acrescentar à referida lista, os surdos. Esses sujeitos que têm sua educação pautada no imperialismo ouvintista e que dependem totalmente da aprendizagem de uma língua oral para adentrar aos espaços sociais, mesmo sendo um indivíduo que não usa a língua oral.

O processo contextualização tem no seu contexto local, o ponto de partida para o desenvolvimento das ações pedagógicas, sendo que ai, o contexto assume o lugar das possibilidades de ampliação e da articulação dos conhecimentos e saberes locais com os globais, num diálogo permanente de aprendizagem, onde, a educação contextualizada não se reduz nem a perspectiva localista, que aprisiona os sujeitos e os conhecimentos ao local, nem a universalista, que termina promovendo o desenraizamento dos contextos em que vivem os sujeitos, mas que efetiva-se, numa prática educativa de sentido e significado, não alienante dos alunos do campo, e que respeita os seus processos de desenvolvimento, as dinâmicas do campo e a relação orgânica entre as condições concretas de existências com o mundo do trabalho e a função social da escola na emancipação desses sujeitos. (REIS, 2009, p.8).

A contextualização na educação urbana deve ter também como ponto de partida o chão que o aluno pisa, esse "chão" torna-se o lugar de articulação entre os conhecimentos locais e os conhecimentos universais.

Embora, o autor do texto concentre seus esforços na "prática educativa de sentido e significado, não alienante aos alunos do campo" (talvez por ser seu foco, no momento), bem como, afirma que tal prática "respeita os processos de desenvolvimentos, as dinâmicas do campo"... É possível pensar a educação urbana com toda essa conjuntura. Afinal, todos os alunos precisam se libertar das alienações dominantes e seu desenvolvimento precisa respeitar as condições concretas de sua existência e a relação com o mundo do trabalho, fazendo desse sujeito um ser ativo e protagonista de sua existência.

A contextualização pode ser pensada nos mesmos princípios, a diferença é que ela se materializará em formatos distintos por ser vivenciada em contextos diferentes, com sujeitos de realidades diferentes, com saberes diferentes, por ter, enquanto eixo norteador, temáticas diferentes. Mas, o princípio será o mesmo: desenvolver os processos educacionais prioritariamente, começando dos conhecimentos adquiridos pelos alunos no seu contexto local para o global. 
Pensar a Educação Contextualizada é algo muito subjetivo que envolve pessoas, pensamentos, cultura e o contexto onde o aluno está inserido, ou seja, o seu cotidiano a sua realidade muitas vezes distantes da vida escolar de vários alunos. Por entender que a educação contextualizada precisa ser construída a partir do conhecimento adquirido dos alunos no seu contexto local e nos saberes existente entre os sujeitos. (LOPES, 2014, p.99).

É necessário sistematizar essa prática, essa nova forma de conceber os processos educacionais e isso é possível a partir da reestruturação do currículo. Nessa perspectiva da contextualização, se faz necessário repensar o currículo considerando o contexto/realidade do aluno, suas vivências e suas especificidades.

A contextualização deixa de ser um adjetivo do currículo e passa a ser um substantivo. Currículo e contextualização são dois elementos tão imbricadamente associados, que o entendimento de um, leva ao aprofundamento do outro e vice-versa, (MENEZES e ARAÚJO, 2007, p.35).

A contextualização advoga por um rompimento com as narrativas universalistas impostas pela concepção colonizadora que impera na educação. Não significa dizer que o aluno não terá os momentos de estudar e fazer as conexões dos conhecimentos locais com os globais, entendendo criticamente quais são seus pontos de ligação, interferências e desligamentos. Para compreender essa teia de relações será necessária, além da contextualização, a interdisciplinaridade, que para Fazenda (2002, p. 41): "O ato de contextualizar exige a virtude primeira da interdisciplinaridade, que é a coerência entre o falar, o pensar e o agir". Ou, como ainda nos ajuda a compreender Hernandez e Ventura (1998, p.54),

A interdisciplinaridade nos é apresentada como uma tentativa de uma organização da informação, dos conhecimentos escolares, partindo de uma visão disciplinar que tenta centralizar-se em alguns temas contemplados a partir de múltiplos ângulos.

\section{Contextualização do sujeito surdo}

A partir de um estudo histórico de Karin Strobel (2009), tem-se a compreensão de que a história da educação dos deficientes auditivos e Surdos é permeada de discriminação, preconceito exclusão e várias teorias na tentativa de comunicação. Ao longo da história houve diversas mudanças na forma de ver 
e tratar esse sujeito. Em um dado período da história, os Surdos eram valorizados e protegidos, pois se acreditava que eram enviados dos deuses até Ihe prestavam adoração (4000 a.C).

Na mesma época também, era possível encontrar quem os considerava exatamente o contrário, castigados pelos deuses. De modo geral, os surdos eram considerados um incômodo para a sociedade. Mesmo existindo pessoas que sinalizavam que o surdo podia se comunicar através dos gestos, a visão que se tinha era de seres incapazes, sem razão e impossibilitados de comunicação. Eles não recebiam herança, não podiam casar, nem votar, era proibido de receber a comunhão, seus direitos eram negados.

A ideia de ensinar ao Surdo era absurda (LUCHESI, 2012). Segundo Strobel (2009), em 1453, o advogado e escritor, Bartollo de Della Marca d'Ancora, fez uma alusão à possibilidade de aprendizagem por meio da língua de sinais. Mas somente 50 anos depois, o médico Girolando Cardano afirmou que a surdez não era impedimento para aprendizagem e que o melhor meio para o ensino era através da escrita, embora ele também usasse a língua de sinais, a qual se modifica de acordo com as variações linguísticas e a cultura de cada lugar. Muitos anos depois John Bulwer (1644), desenvolveu um método de comunicação entre ouvintes e surdos. Seguidor dos métodos de Bonet, John Wallis (1659), fundadores do oralismo. Ele desistiu de ensinar o surdo a falar, usava a Língua de Sinais, pois considerava seu uso importante para ensinar os surdos. Houve quem discordasse dessa concepção. Johann Conrad Amman (1700 - Alemanha) era contra a língua de sinais, pois dizia que "atrofia a mente". Mas usava sinais e alfabeto digital como instrumento para atingir a fala. Já o Abade Charles Michel de L'Epée, defendia a língua de sinais como um verdadeiro meio de comunicação e de desenvolvimento do pensamento. Ele publicou o primeiro dicionário de sinais, além de fundar 21 escolas para Surdos na França e na Europa. Contra essa concepção surge na história, o médico cirurgião e psiquiatra Jean Marc Gaspardltard (1802), defendendo a ideia de que as sensações eram a base para o conhecimento humano e somente a experiência externa era fonte de conhecimento.

Nesse sentido, era necessária a erradicação ou diminuição da surdez para que o Surdo tivesse acesso ao conhecimento. Ele fez vários experimentos para descobrir as causas visíveis da surdez que passa a ser tratada como doença. Afirmava que o Surdo podia ser treinado para ouvir palavras, afirmava que o ensino de língua de sinais implicava o estímulo de percepção de memória, de atenção e dos sentidos. Unificando as teorias dos dois teóricos anteriores, Grahn Bell (1846), professor de Surdos, defendia a ideia de que a língua de sinais deveria ser utilizada como apoio à Língua Oral. Criticou o casamento entre surdos, pois dizia que isso era uma forma de isolamento e não contribuía para o desenvolvimento intelectual dos surdos. 
No Brasil, segundo Strobel (2009), a história dos Surdos começa com a vinda de Eduardo Huet, professor Surdo com experiência de mestrado e cursos em Paris (26 de setembro de 1857- hoje dia Nacional dos Surdos no Brasil). Ele chega e com o apoio do imperador D.Pedro II, abre uma escola para pessoas surdas. A escola recebia Surdos de todas as partes do Brasil e foram os alunos que difundiram o alfabeto manual de origem francesa e misturam com os sistemas já usados pelos Surdos de várias regiões do Brasil, a LIBRAS (Língua Brasileira de Sinais). Em 1957 foi fundado no Brasil, o Instituto Nacional de Educação dos Surdos - INES.

$\mathrm{Na}$ época proibiram a língua de sinais oficialmente nas salas de aula, mesmo com a proibição os alunos surdos continuaram usar a língua de sinais nos corredores e nos pátios da escola. Para minimizar os prejuízos causados pela falta de parâmetro educacional, depois de muitos anos de lutas, a partir da década de 90, têm sido criadas leis que regulamentam o ensino para alunos Surdos, definindo a formação dos profissionais, métodos, currículos, recursos, estruturas físicas, formas de atendimentos e o direito a inclusão nas salas comuns das escolas. Nesse sentido a leis 10.436/2002 e o decreto 5.626/2005 tem efetivamente feito a diferença nessa modalidade educacional, ratificando os direitos desses sujeitos já concedidos na Constituição Federal de 1988, Lei de Diretrizes e Bases (9394/96-LDB), Estatuto da criança e do Adolescente (8.069/90-ECA).

Segundo o decreto 5.625 de dezembro de 2005, considera-se pessoa surda aquela que, por ter perda auditiva, compreende e interage com o mundo por meio de experiências visuais, manifestando sua cultura principalmente pelo uso da Língua Brasileira de Sinais - Libras.

Esses sujeitos têm direito à escolarização em um turno diferenciado do seu horário de aula comum. Esse atendimento educacional especializado, tem como objetivo o desenvolvimento de complementação curricular, com utilização de equipamentos e tecnologias de informação adaptadas para atender às suas necessidades específicas. Esse atendimento é feito por um professor bilíngue. Ele fará a complementação curricular, da base nacional comum, com o ensino da língua brasileira de sinais-libras e o ensino da modalidade escrita da Língua Portuguesa, como segunda língua para alunos surdos. A mesma, deve ser ministrada em uma perspectiva dialógica, funcional e instrumental.

\section{Aplicando o Conceito de Contextualização}

A seguir serão apresentados e utilizados alguns conceitos de contextualização concebidos a partir do estudo feito sobre o referido tema, "Educação Contextualizada". Porém, com sentido mais específico para o estudo em questão. Apoiando-se no que diz Fazenda (2002, p.41), 
A contextualização é um ato muito particular e delicado. Cada autor, escritor, pesquisador ou professor contextualiza de acordo com suas origens, com suas raízes, com o seu modo de ver e enxergar as coisas, com muita prudência, sem exagerar.

Espera-se que esse pensar não esteja desvirtuando o real sentido da "Contextualização", amplamente pregada por autores/pesquisadores renomados na área. Contextualização aqui, é o ato de reunir todas as informações referentes à determinada situação, fazendo conexão entre os elementos que compõe um contexto, com o objetivo de demonstrar os conceitos e conteúdos que precedem a situação, assim, para realidade que iremos analisar a Contextualização pode ser ainda, entendida como a ação de descrever detalhadamente um objeto de estudo.

Contextualização pode ser concebida também, como 0 ato de desenvolver análises de códigos utilizados como meios de comunicação; e mais, contextualização pode ser, apresentar os signos: significados e significantes que compõem um enunciado.

O aluno chegou à sala de aula, pedindo ajuda para responder a questão apresentada na figura 1. Porém, no momento da leitura do problema, o professor percebeu que ele não estava entendendo a questão porque não compreendia 0 significado das palavras inseridas no enunciado. Foi necessário contextualizar quase todas as palavras. O professor fez da seguinte forma:

a) Elaborou uma aula trabalhando o gênero feminino e masculino/palavras masculinas e femininas.

Objetivo: ensinar o que significa a palavra "brasileiro", exercitando a escrita da referida palavra.

b) Trabalhou os substantivos próprios e comuns (foco em nomes de pessoas e lugares).

Objetivo: ensinar o que significa a palavra "Joaquim Cruz" e "Los Angeles", exercitando a escrita da referida palavra.

c) Desenvolveu uma aula sobre esportes, trabalhando os conceitos de: competição, premiação (medalha de bronze, prata, ouro, pódio) olimpíadas, etc.

Objetivo: ensinar o que significa a palavra "ouro", exercitando a escrita da referida palavra.

d) Elencou alguns verbos e pronomes para explicar as ações expressas na questão.

Objetivo: ensinar o que significa a palavra "ganhar", "correr", exercitando a escrita das referidas palavras.

e) Preparou uma aula sobre tempo - dia, noite, mês, ano, hora, minuto, segundo, relógio.

Objetivo: ensinar o que significa 100 s. 
f) Estudo sobre espaço, distância, tempo, velocidade, variação...

Objetivo: possibilitar o entendimento da questão.

Figura 1: Fotografia do caderno do aluno contendo questão de física

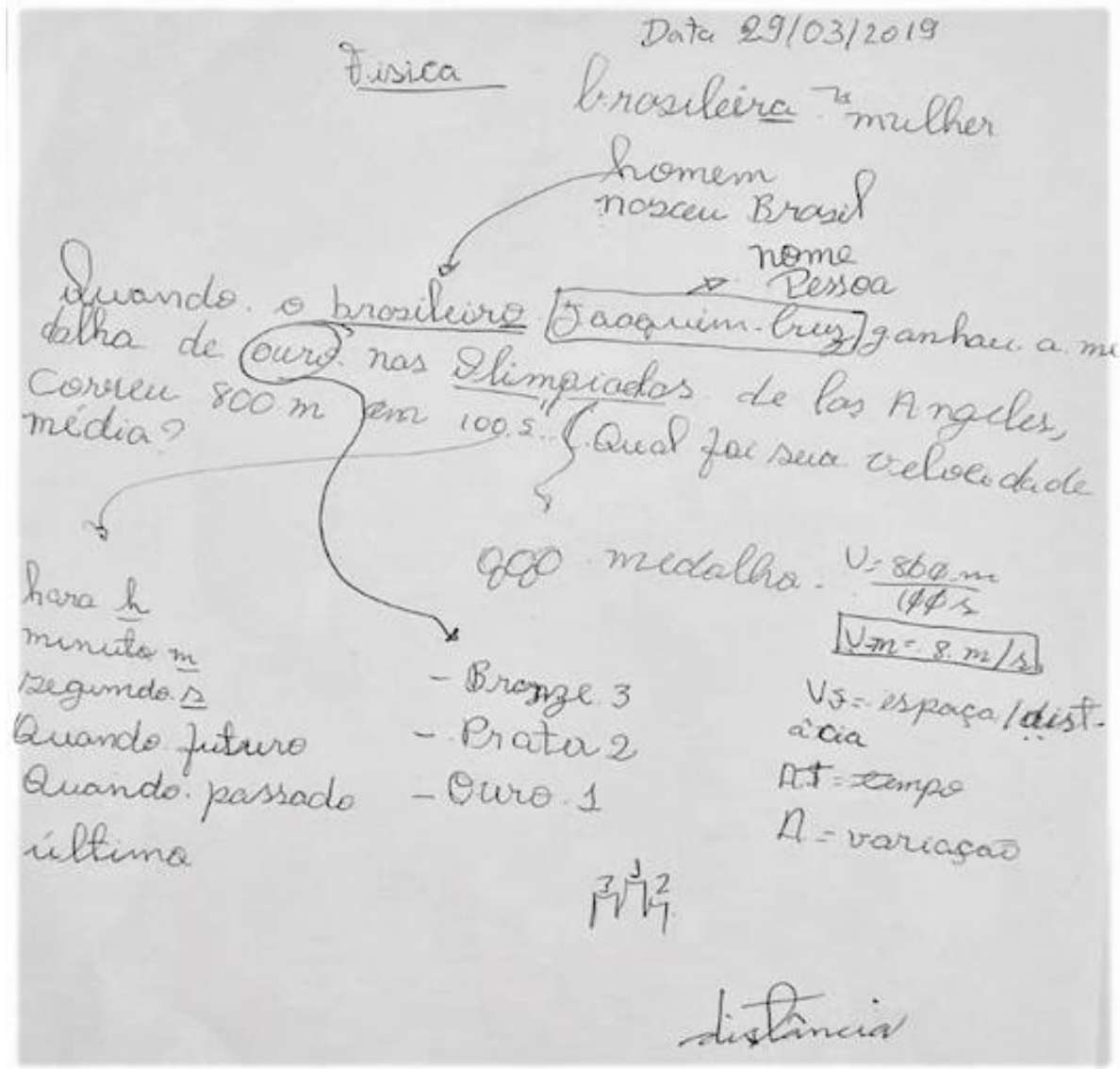

Fonte: autor.

Por fim, a resolução da questão de física propriamente dita. Todas as ações explicadas com recursos de imagens, fazendo ligação do conteúdo com situações reais cotidianas, sempre desenhando um contexto, e de forma muito repetitiva. Porque, segundo o professor, o aluno surdo aprende a escrever em português dessa forma, repetindo, repetindo. Acredita-se que isso é contextualização.

Isso é, contextualização, é dar sentido e significado a proposição didática, pois se assim, não for, pouco se acrescenta, já que ensinar e aprender não são sinônimos e não acontecem imediatamente um ao outro. O desafio é tentar integrá-los, o que exige uma maior atenção aos processos individuais $e$ as singularidades desses dois processos, complementares, mas não similares. (REIS, 2009, p. 229). 
É o processo de dar sentido para o desconhecido. Assim, é possível transmitir uma ideia ou conhecimento e observar sua captação por meio das respostas do aluno. É por intermédio desta dinâmica que durante a contextualização, podemos dar as mãos aos nossos alunos e caminhar com eles na certeza de que houve aprendizagem significativa porque eles conseguiram compreender e apreender todo o contexto que precedeu o conteúdo ensinado.

Depois que $o$ aluno compreendeu os significados das palavras e o que elas representavam na questão ficou bem mais fácil respondê-la. Ele retomou a questão com outro olhar depois de quatro dias de estudos.

A contextualização se dará no momento em que se retorna a essa realidade, com um novo olhar, com possibilidades de compreensão e ação. A contextualização sucede a problematização e a teorização ou modelização. Ê na etapa da modelização que os saberes a ensinar serão trabalhados. Ela responde, em certo sentido, à seguinte pergunta: que saberes são necessários para se compreender a situação-problema que se apresenta nesse momento? $\hat{E}$ por isso que tal situação tem de ser construída. Ela não é dada nos programas ou livros didáticos. (CARVALHO, 2010, p.44).

Pode haver equívoco nessa compreensão como já foi assinalado anteriormente, mas é possível perceber uma ligação, ainda que não seja perfeita, porém com fortes indícios de conexão entre contextualização e o processo de ensino descrito nessa experiência. É interessante ressaltar que independente da conexão existir ou não, se faz necessário alargar essa discussão buscando um entendimento mais profundo que contemple outras questões de ensino que não sejam apenas local, rural, ambiental, mas que vise o universo educacional da região semiárida como um todo.

\section{Método}

Caracterização da Pesquisa

O estudo ora apresentado tem caráter qualitativo, descritivo e os seus resultados foram analisados com base na relação prática do sujeito com 0 contexto escolar. Optou-se pela abordagem qualitativa,

Visto que permitem aproximação com a subjetividade do sujeito, podendo, dessa maneira, revelar ou ao menos aproximar de seus sentidos e significados, ao mesmo tempo em que estabelece articulações com as bases teóricas. (SILVA, 2018, p. 29). 
A natureza descritiva da pesquisa deu-se em função de compactuar com o pensar de Triviños, (1987), ao afirmar que o delineamento descritivo consiste na ideia de que a pesquisa descritiva exige do investigador uma série de informações sobre o que deseja pesquisar. Esse tipo de estudo pretende descrever os fatos e fenômenos de determinada realidade.

\section{Participantes e Instrumentos para Coleta de Dados}

Participaram desse estudo um professor e um aluno, ambos de uma Escola Pública Estadual, localizada na cidade de Petrolina-PE, sendo que, para preservar a identidades dos envolvidos serão usados nomes fictícios.

A pesquisa é fruto de uma semana de participação e observação nas aulas de Atendimento Educacional Especial (AEE), realizadas pelo professor João Vicente, instrutor da língua brasileira de sinais (LIBRAS), que assiste 0 aluno Luiz Fernando, que é surdo, cursa o $1^{\circ}$ ano do Ensino Médio e vem à sala de AEE para ser assistido nas atividades pedagógicas.

$\mathrm{O}$ atendimento dado ao aluno acontece com base em três momentos didático-pedagógicos: atendimento Educacional Especializado para o Ensino em LIBRAS, que é o momento de estudar o conteúdo que foi dado na sala regular de forma mais detalhada, em LIBRAS.

O Atendimento Educacional Especializado para o Ensino de LIBRAS é o momento de estudar a língua brasileira de sinais LIBRAS, que é uma língua, visual/espacial, com estrutura própria, que ajudará o aluno no desenvolvimento linguístico, comunicativo e servirá como mediadora na aprendizagem da língua portuguesa como segunda língua na modalidade escrita.

E o Ensino Educacional Especializado em Língua Portuguesa, é o momento do ensino do português escrito, como segunda língua L2, para o aluno surdo. Esse último momento, chamou a atenção porque o professor consegue realizar o estudo da língua portuguesa em todas as atividades, independente das disciplinas. Os referidos momentos irão subsidiar o aluno na efetivação de sua aprendizagem em sala de aula comum.

Porém, diante das grandes dificuldades enfrentadas por Luiz Fernando, para acompanhar o processo de ensino aprendizagem na sala de aula regular, o professor João Vicente se propôs a ministrar aulas de reforço (embora essa não seja a sua função), realizando as atividades de casa com o aluno.

Como técnica de coleta de dados utilizou-se da observação, para perceber quais estratégias seriam usadas pelo professor para ensinar os diversos conteúdos da matriz curricular do ensino médio. Neste caso, o foco foi 
em um exercício de física, que exigiu uma semana inteira para trabalhar o enunciado e só então, ir para resolução propriamente dita, da questão.

\section{Procedimento de Coleta de Dados}

Foi apresentado um ofício à gestão da escola solicitando autorização para frequentar as aulas do professor João Vicente, como observadora e participante do processo, explicando que a intenção era observar a metodologia de ensino do referido professor.

Foram disponibilizadas várias atividades feitas anteriormente para possíveis análises e indagações referentes aos modos como elas foram realizadas.

Após a autorização, aconteceram 5 visitas à escola, cada uma como uma carga horária de $5 \mathrm{~h} / \mathrm{a}$, totalizando $25 \mathrm{~h} / \mathrm{a}$. Durante esses dias o foco da observação centrou na metodologia/estratégia de ensino.

\section{PALAVRAS FINAIS}

Ao ler ou ouvir a palavra "contextualização", vem à mente a imagem de professores realizando suas aulas no campo = zona rural. Professores que conhecem bem o entorno de suas escolas, seus alunos, suas vivências e suas comunidades. Esse professor adota como procedimentos metodológicos a contextualização, que se resume, muitas vezes, ao ato de ensinar os conteúdos do currículo tomando como ponto inicial a realidade do aluno.

Pode até ser um equívoco visualizar essa imagem, porém, é o que tem sido disseminado na maioria dos discursos sobre contextualização. É como se isso somente fosse possível no campo/zona rural.

A ideia desse relato foi apresentar a contextualização através de outro olhar, não menos importante, prático e viável. O objetivo foi transpor essa limitação "local", "rural", e apresentar a contextualização presentes em práticas pedagógicas urbanas e dizer que ela surge, algumas vezes, por força da necessidade, como foi o caso apresentado.

A ausência da contextualização torna o processo cognitivo insuficiente, pois as condutas se aprendem, e são aprendidas em um ambiente, e todos os ambientes tem capacidade de educar se soubermos percebê-los e nos relacionar com eles significativamente. (KUSTER, MATTOS, 2004, p.22). 
Acredita-se que "ambiente", na citação, não se restringe a "lugar". Pode ser um código, uma situação, signo, um objeto... Ou será que não?

Algumas situações de ensino aprendizagem, por si só evocam a contextualização e, no ensino aprendizagem dos alunos surdos, em especial, essa contextualização é obrigatória. Há um trabalho intercultural, bilíngue, isso exige uma interação especial entre os sujeitos envolvidos no processo. Entendese que,

A concepção da educação contextualizada busca entender que as pessoas se constroem e constroem seu conhecimento a partir de seu contexto, com relações mais amplas. Ou seja, a relação, ou a construção de saberes, se dá na relação das pessoas com o mundo, consigo mesmo e com os outros. (MENEZES e ARAÚJO, 2007, p. 42).

É óbvia a necessidade da contextualização do ensino, pois ela é vista como uma das formas de melhorar a aprendizagem e estimular o interesse dos educandos na busca da construção do conhecimento. Já não há mais espaço para o tradicionalismo formal, para currículos cartesianos e métodos lineares. É preciso que os professores renovem seus métodos, que desenvolvam dinâmicas em sala de aula, que facilitem a interação sujeito-conhecimento. A contextualização é o caminho a seguir, pois tem por objetivo ajudar o aluno na problematização dos saberes a serem apreendidos, despertando a curiosidade do aluno para os conhecimentos que ele ainda não tem.

A escola precisa desenvolver um Projeto de Formação Continuada para os/as Professores/as, indicando novos olhares, reflexão e análise sobre suas práticas pedagógicas em sala de aula, propor novas metodologias, estimulandoos/as a fazerem uso de situações reais relacionados às disciplinas e ao currículo.

Ao selecionar os conteúdos da série em que irá trabalhar, o professor precisa analisar os textos, verificar como são abordados os assuntos para enriquecê-los com sua própria contribuição e a dos alunos, comparando o que se afirma com fatos, problemas, realidades da vivência real dos alunos (...) (LIBÂNEO, 1990, p.85).

O professor deve trabalhar a sua disciplina, através da proposta de contextualização e da interdisciplinaridade. A contextualização é entendida aqui como sendo "o ato de vincular o conhecimento à sua origem e à sua aplicação". É do conhecimento de todos que essa forma de ensino é um instrumento fundamental e imprescindível para melhoria no desenvolvimento de todo o educando, para sua inserção nas questões sociais, vivenciadas no seu tempo e espaço e para sua integração no processo educacional. 
A adoção de práticas fundamentadas na contextualização e nos processos de interdisciplinaridade são benéficas não somente para alunos com surdez, mas igualmente, para os alunos ouvintes pois, visa a compreensão efetiva dos conteúdos, constituindo pontes entre o teórico e o prático. Nessa discussão, a contextualização está sendo colocada na função de ampliação do vocabulário do aluno.

É comum ouvir o aluno dizer que não entendeu a pergunta da prova, da atividade, do exercício; quando questionado sobre a falta de entendimento, o aluno destaca as palavras desconhecidas que o impediu de compreender o enunciado proposto. Muitas vezes os professores elaboram suas atividades fazendo uso de enunciados prontos de livros, listas de exercício de internet e outras fontes, não se preocupam se o que está sendo posto é do domínio de seu aluno.

É necessário compreender a importância da contextualização no processo de ensino-aprendizagem em qualquer disciplina. Contextualizar é tornar acessível ao aluno a representação presente no texto (no caso, o enunciado). Isso facilitará a assimilação dos conteúdos e o desenvolvimento de novas habilidades, pois envolve o entendimento do texto, domínio do vocabulário especifico, entre outras habilidades. Portanto é preciso abandonar a ideia de que desenvolver essas habilidades é responsabilidade do professor de português, afinal, a língua está presente em todas as disciplinas e dela dependem todos os processos comunicativos. A contextualização irá proporcionar a interação/conexão, entre o aluno e o conhecimento.

Segundo os PCNs (2001) para o Ensino Fundamental, a ideia da contextualização requer a intervenção do estudante em todo o processo de aprendizagem, fazendo as conexões entre os conhecimentos. Assim, esse aluno que estará na vanguarda não será nunca um expectador, um acumulador de conhecimentos, mas um agente transformador de si mesmo e do mundo.

Para facilitar o processo de contextualização é de extrema necessidade que os/as professores/as se unam na dinâmica de ensino, trabalhando de forma interdisciplinar, minimizando a fragmentação dos conteúdos.

Os professores precisam refletir sobre suas práticas, planejar efetivamente suas atividades, respeitando a realidade do aluno, considerando as limitações de cada um e buscando aplicar os conhecimentos adquiridos.

Caso o professor não assuma essa postura, seu trabalho será ineficiente, uma vez que a metodologia é determinante para o sucesso do aluno, é ela que vai facilitar a assimilação dos conteúdos, a memorização e a aplicabilidade dos mesmos. Nessa concepção não basta ter uma variedade de conhecimentos teóricos, é necessário saber transmitir com eficiência e de forma significativa os conteúdos. 


\section{REFERÊNCIAS}

BRASIL. Decreto n. 5.626/05, de 22 de dezembro de 2005. Diário Oficial da União, Poder Legislativo, Brasília, DF, 22 de dez. de 2005. Disponível em: http://www.planalto.gov.br/ccivil_03/_ato2004-2006/2005/decreto/d5626.htm. Acesso em: 03 de set.2016.

BRASIL. Estatuto da Criança e do Adolescente: Lei n.8.069/90, de 13 de julho de 1990. Diário Oficial da União, Poder Legislativo, Brasília, DF 13 de JL 1990. Disponível em: http://www.planalto.gov.br/ccivil_03/leis/L8069.htm. Acesso em: 03 de set.2016.

BRASIL. Lei de Diretrizes e Bases: Lei n.9394/96, de 20 de dezembro de 1996. Diário Oficial da União, Poder Legislativo, Brasília, DF 20 de dez. 1996. Disponível em: http://www.planalto.gov.br/ccivil_03/leis/L9394.htm. Acesso em 30 de ago. 2016.

BRASIL. Lei n. 10.436/02, de 24 de abril de 2002. Diário Oficial da União, Poder Legislativo, Brasília, DF 24 de abr. de 2002. Disponível em:

http://www.planalto.gov.br/ccivil_03/leis/2002/L10436.htm. Acesso em 03 de set. 2016.

BRASIL. Secretaria de Educação Fundamental. Parâmetros curriculares Nacionais: introdução aos parâmetros curriculares nacionais / Secretaria de Educação Fundamental. - Brasília: MEC/SEF, 2001. 126, p. 1.

CARVALHO, Anna Maria Pessoa de. Ensino de física [et al.]. - São Paulo: Cengage Learning, 2010. - (Coleção ideias em ação).

FAZENDA, Ivani C. A. (org.). Dicionário em construção: interdisciplinaridade $-2^{a}$. ed. - São Paulo: Cortez, 2002.

HERNÁNDEZ, F; VENTURA, M. A organização do currículo por projetos de trabalho: O conhecimento é um caleidoscópio. Porto Alegre: ARTMED, 1998.

HONORA, Márcia. Inclusão Educacional de alunos com surdez: concepções e alfabetização: ensino fundamental, 1ํㅜciclo. - São Paulo: Cortez, 2014.

KUSTER, Ângela Beatriz. MATTOS, Helena Oliveira de Mello. (org.). Educação no Contexto de Semi-árido Brasileiro.- Fortaleza: Fundação Konrad Adenauer, 2004.214p.

LIBÂNEO, J. C. Didática. São Paulo: Cortez, 1990

LOPES, Maria Letícia. Educação contextualizada voltada para a realidade dos sujeitos que vivem no semiárido. In: NEPEC-SAB. Itinerários \& Contextos: reflexões em educação e convivência com o semiárido brasileiro. Juazeiro: NEPEC-SAB, 2014.

MARTINS, Josemar da Silva. Anotações em torno do conceito de educação para a convivência com o Semiárido. In: RESAB. Educação para a Convivência com o Semiárido Brasileiro - reflexões teórico-práticas da RESAB. Juazeiro - BA: Secretaria Executiva da RESAB, 2006.

MENEZES, Ana Célia. ARAUJO, Lucineide Martins. Currículo, Contextualização e Complexidade: espaço de interlocução de diferentes saberes. In: Caderno Multidisciplinar-educação e Contexto do semi-árido Brasileiro: Currículo, 
Contextualização e Complexidade: elementos para se pensar a escola no semiárido.v.1 - Juazeiro/BA: selo editorial RESAB, 2007.

QUADROS, Ronice Muller de. Educação de surdos: a aquisição da linguagem. Porto Alegre: Artmed, 2008.

REIS, Edmerson dos Santos. (2009). A contextualização dos Conhecimentos e saberes escolares nos processos de reorientação curricular nas escolas do Campo. Tese de doutorado apresentada ao Programa de Pós-Graduação em Educação da Universidade Federal da Bahia. Salvador; 2009.

SILVA, Raimunda Magalhães da. et al (orgs). Estudos Qualitativos: Enfoques teóricos e técnicas de coletas de informações. - Sobral: Edições UVA, 2018,305 p.

STROBEL, K.L. A História de Educação dos Surdos. Apostila do curso de Licenciatura de letras/LIBRAS da UFSC, Florianópolis: 2009. Disponível em: http://www.libras.ufsc.br/colecaoLetrasLibras/eixoFormacaoEspecifica/historiaDaEduca caoDeSurdos/assets/258/TextoBase_HistoriaEducacaoSurdos.pdf. Acesso em $25 / 07 / 2016$

TRIVIÑOS, Augusto Nibaldo Silva. Introdução à pesquisa em ciências sociais: a pesquisa qualitativa em educação. --São Paulo: Atlas, 1987. 